\title{
Taxation students' perceptions of open-book assessment: a follow-up interactive qualitative analysis
}

\author{
Hanneke Du Preez* \\ Department of Taxation, University of Pretoria, South Africa \\ ^Email: Hanneke.DuPreez@up.ac.za
}

\begin{abstract}
Students' perceptions of a particular assessment type seems to influence their attitude to preparing for and taking the assessment. The literature suggests that open-book assessment allows a better understanding of the content of a subject area, thus better preparing students for real-life situations. Hence, this study sought an in-depth understanding of taxation students' perceptions of open-book assessment in the process of qualifying as chartered accountants. Using already published findings on a focus group of taxation students' perceptions prior to exposure to open-book assessment, an interactive qualitative analysis (IQA) method was again adopted to analyse interviews with taxation students on their perceptions of open-book assessment after exposure to such assessment. The new findings were compared to those for the focus group. The affinities that emerged from the focus group study elicited various comments from the interviewees. One difference between the two groups was that the focus group saw the different approach affinity as the final outcome of the system created by the IQA, while the interviewees regarded this affinity as the system's primary starting point. Secondary differences between the two groups pertained to the affinities encouragement, improved quality of answers, negative environment and time management. The groups agreed on good preparation, back-up, general advantages and negative symptoms of openbook assessment. This study concludes that when students need to be prepared for open-book assessment, the different approach affinity should be a point of departure.
\end{abstract}

Keywords: Open-Book Assessment, Interactive Qualitative Analysis, Focus Group, Interview, Perceptions

\section{Introduction}

For most students, the mere idea of being assessed creates stress, and even anguish (Msila, 2011). Students' perceptions of a specific assessment type appear to influence their attitude towards both preparing for and taking the assessment (Du Preez \& Du Preez, 2012; Struyven, Dochy, \& Janssens, 2002) ${ }^{1}$. There also seems to be a link between a student's study profile, assessment preference and final achievement (Karagiannopoulou \& Milienos, 2013).

There are many different definitions of assessment, but for the purposes of this study, assessment can be broadly defined as any systematic procedure for collecting information that can be used to make conclusions for educational purposes about the characteristics of 
people or objects at different levels (AERA, 1985; Reynolds, Livingston, \& Willson, 2006). One way to categorise assessment is closed-book versus open-book. In an open-book assessment, unlike in a closed-book assessment, students are allowed to consult textbooks, notes and/or other materials while completing the assessment (Agarwal \& Roediger, 2011; Koutselini-Ioannidou, 1997; Westerkamp, Heijne-Penninga, Kuks, \& Cohen-Schotanus, 2013). There are different applications, with possible stipulations about which resources are permitted in a particular assessment situation. For the purposes of this research, open-book assessment is defined as an assessment type where candidates have access to various supporting resources during the assessment situation.

Research suggests that students in closed-book assessment situations appear more anxious than those attempting an open-book assessment (Theophilides \& Koutselini-Ioannidou, 2000; Msila, 2011). Students also appear to be less positive about closed-book assessment than students answering an open-book assessment (Theophilides \& Dionysiou, 1996). When it comes to the effectiveness of these two types of assessment, some findings indicate that the long-term retention and transfer of knowledge is at a higher level with closed-book assessment than with open-book assessment (Agarwal \& Roediger, 2011). Conversely, some studies suggest that open-book assessment does have benefits, in that it creates a better understanding of the content of a subject area, and therefore better prepares students for real-life situations (Baillie \& Toohey, 1997; Durham, 1990; Eilertsen \& Valdermo, 2000; Feller, 1994; Kelly, 2013; Theophilides \& Koutselini-Ioannidou, 2000). Boniface (1985) cautions that when students have access to notes, textbooks and/ or other resources in an assessment, this might discourage them from preparing thoroughly because they know they will have all the allowable resources at hand. Moreover, Msila (2011) found that in an open-book assessment, some students simply copy answers from sources, with no application of critical thought.

Open-book assessments are now used in the accountancy training field in South Africa in line with the requirements prescribed by the South African Institute of Chartered Accountants (SAICA, 2009). In 2004, SAICA changed its assessment policy regarding the Qualifying Examination (QE) Part 1 for chartered accountants from a traditional closed-book to an alternative open-book assessment. According to SAICA, the aim of this examination is to assess the integrated application and cognitive knowledge of a candidate. This pertains to all four major subject areas, namely Auditing, Taxation, Financial Accounting and Management Accounting (Coetzee \& Oberholzer, 2012). The requirements of this governing body were considered in this study because the participants in this research wanted to become chartered accountants.

In view of the inconclusive prior findings on the benefits and/or drawbacks of openbook assessment, a general lack of understanding in the literature on students' perceptions of assessment types, and SAICA's use of open-book assessment, the focus of this study was perceptions of open-book assessment among taxation students. This study is a follow-up on previous research conducted on students' perceptions of openbook assessments prior to any exposure to open-book assessment (Du Preez \& Du Preez, 2012). The previous study used the interactive qualitative analysis (IQA) methodology (Northcutt \& McCoy, 2004) to conduct a focus group. The findings of the focus group study by Du Preez and Du Preez (2012) were referred to in the interviews in the current study. Thus, this research reports on the findings from the interviews, and then compares the perceptions found in the focus group study and those expressed during the interviews. 


\section{Research methodology and findings}

The earlier focus group study (Du Preez \& Du Preez, 2012) identified a number of affinities, which can be defined as the themes generated in an IQA process by the focus group regarding perceptions of open-book assessment. Throughout the current article, brief references are made to this prior focus group study. The participants in the focus group study were identified B Com (Honours) Accounting students at the University of Pretoria with Taxation as a major subject. This group of students was selected because they had no prior experience of, or exposure to, open-book assessment.

The second phase of the research as reported in the current article commenced where the affinities were introduced to interviewees who did have experience of open-book assessment for their comment and critique. The IQA method was again applied throughout. IQA is a qualitative method of research that involves a detailed, application-oriented systematic process by which data, analysis and interpretation are merged as a whole (Northcutt \& McCoy, 2004). The focus group generated affinities through a structured process, as recommended by Mampane and Bouwer (2011; cf. Du Preez and Du Preez, 2012). These affinities were presented to the interviewees during semi-structured interviews to gain further insight into the affinities. The possible relationships between the affinities were discussed throughout the IQA process.

\section{Participants}

This research was conducted at the University of Pretoria in South Africa among taxation students in the Department of Taxation.

The aim of this research was to use the affinities that emerged from the focus group study (using participants with no experience of open-book assessment) and to use them as a starting point when conducting interviews with participants with experience of, or exposure to, open-book assessment.

The group of students identified as the population for the interview study were M Com (Taxation) students in the Department of Taxation at the University of Pretoria. These students were invited via email to participate in the study. Five students who responded conformed to the requirements, and all five consented to a personal interview. This non-probability conveniencetype sampling to select interviewees was adopted to gain specific information about perceptions of open-book assessment from an accessible group who have experienced this phenomenon and have something to say about it, as recommended by Cooper and Schindler (2003).

The criteria for inclusion were that these students had to be M Com students, and that they had to have a history of experiences with open-book assessment. The interviews were conducted between June and August 2010 after the interviewees had completed the QE Part 1, as well as the M Com examination, both of which involve open-book assessment. The same exploration framework as that used in the focus group study was employed, and the affinities that emerged in the previous study were included during the semi-structured interviews. This design was chosen because it focused on exploring and identifying themes pertaining to a specific phenomenon (Creswell, 2002) - in this case, perceptions of open-book assessment - allowing a more nuanced understanding of the phenomenon under review.

\section{Focus group}

\section{Data collection}

For the purposes of this paper, the findings of the focus group study were used as the baseline data referred to, and compared to the data generated in the interviews. 
In the focus group study, a document was compiled containing the affinities and the participants' descriptions of them. The identified affinities were:

- good preparation (the importance of knowledge gained prior to attempting the openbook assessment, but also concentrating on forming a referencing habit);

- back-up (textbooks could be used as a mode of reference to help eliminate various options and find the correct wording);

- encouragement (an optimistic effect on students writing an open-book assessment);

- general advantages (the textbook used in open-book assessment is a visual tool for accessing memorised detail);

- improved quality of answers (the availability of textbooks provides more detail than can be memorised);

- negative symptoms (the time-consuming process of preparing the textbook for the examination and the intellectual preparation of the students themselves are eliminated);

- negative environment (during an open-book assessment, students tend to page through textbooks, creating disturbance and disruption);

- personal experience and hindrance (open-book assessment was perceived as more difficult and demanding, as the availability of textbooks might lead to excessive checking of answers, and was consequently an unnecessary waste of time);

- different approach (the mental and emotional change in preparation necessitate adjustment when preparing for open-book assessment, compared with closed-book assessment); and

- time management (the effective management of time when preparing for and during the assessment, as well as accepting that the tools available should be used only when absolutely necessary) (Du Preez \& Du Preez, 2012).

Once the definition for each affinity was finalised, a system influence diagram (SID) was compiled by the researchers for the relationships between the affinities indicated by the participants in the focus group (Du Preez \& Du Preez, 2012). A SID represents the relationships between the different affinities in a system - affinities may influence each other, or they may in turn be influenced by other affinities. An affinity that influences other affinities is called a primary driver (PD). An affinities that is only influenced by other affinities is called a primary outcome (PO). An affinity that equally influences other affinities and is influenced by other affinities is called a pivot (P). A secondary driver (SD) is an affinity that mainly influences other affinities, but which is, to a lesser extent, influenced by other affinities. A secondary outcome (SO) is one that is mainly influenced by other affinities, but which also influences other affinities (Northcutt \& McCoy, 2004).

The classification of the affinities from the focus group study (Du Preez \& Du Preez, 2012) is summarised as tentative SID assignments in Figure 1.

The SID (Figure 2, below) consists of ten interacting affinities (see Figure 1). The SID shows no primary driver; the strongest secondary driver is good preparation. The primary outcomes identified by the focus group were time management, negative symptoms of openbook assessment, and different approach, as these had no impact on the other affinities. Two feedback loops are present in this system, and they revolve around good preparation. These feedback loops are interactive, and in turn influence each other (Du Preez \& Du Preez, 2012). 


\begin{tabular}{|l|l|}
\hline Affinity & Assignment \\
\hline Good preparation & Secondary driver \\
\hline Improved quality of answers & Secondary driver \\
\hline Back-up & Secondary driver \\
\hline Encouragement & Secondary driver \\
\hline Negative environment & Secondary driver \\
\hline Personal experience and hindrance & Circulator/pivot \\
\hline General advantages & Secondary outcome \\
\hline Negative symptoms & Primary outcome \\
\hline Different approach & Primary outcome \\
\hline Time management & Primary outcome \\
\hline
\end{tabular}

Figure 1. Tentative SID assignments from the focus group study.

The first feedback loop commences with good preparation. There was a perception that a student who is well prepared for an open-book assessment has more effective access to the resources allowed in the assessment venue. If these resources are prepared before the assessment, they can be used during the assessment as a back-up. The focus group members argued that this could lead to general advantages, for example, the need to memorise technical detail would be reduced, because students would have access to textbooks containing the relevant information. They indicated that increased access to detail might improve the quality of answers, and felt that students could expand their answers to include easily forgotten facts, formulae and complex definitions (Du Preez \& Du Preez, 2012).

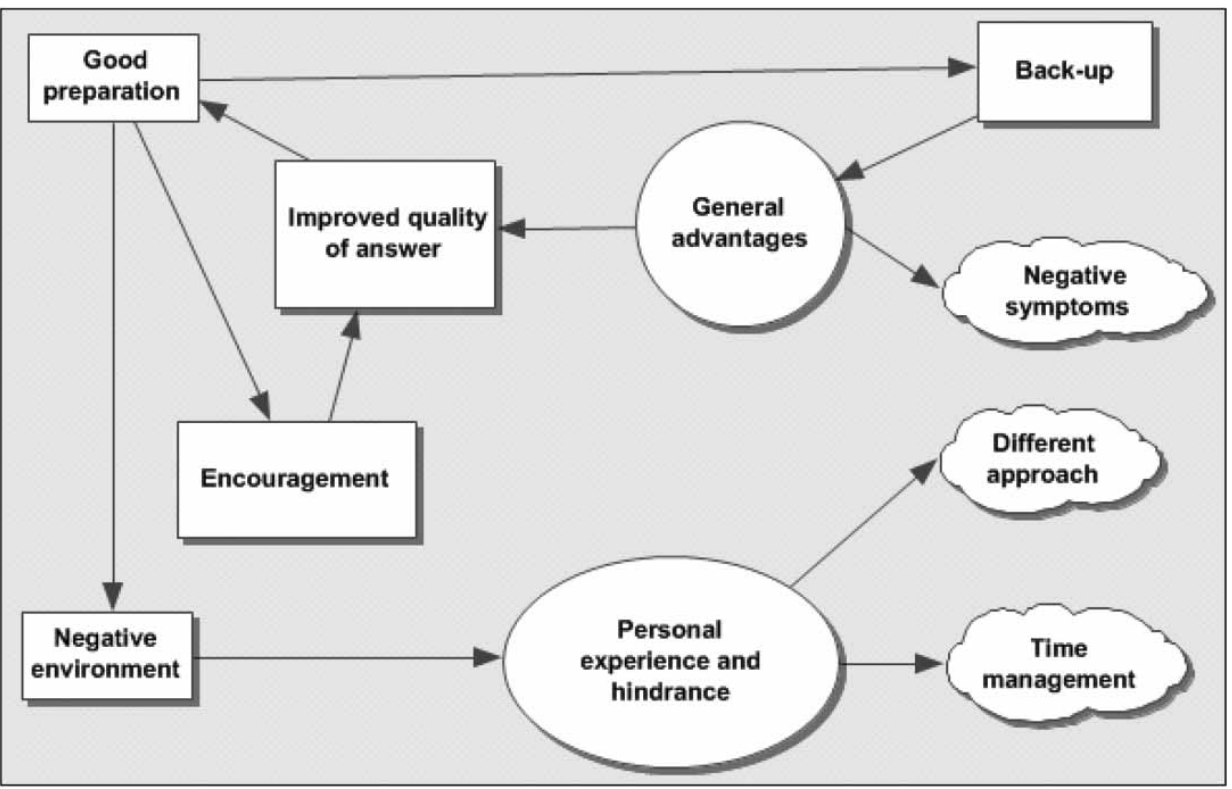

Figure 2. SID from the focus group study (adapted from Du Preez \& Du Preez, 2012). 
The second feedback loop also starts with good preparation. The focus group believed that open-book assessment could create a feeling of encouragement to boost candidates' confidence in their own abilities, brought about by the accessibility of resources. The focus group also argued that open-book assessment appeared to have a motivational effect when the assessment was attempted. They said this resulted in an improvement in the quality of answers. The participants believed that the more success students had in open-book assessment, the more encouraged they would feel about preparing for the next assessment, after which the feedback loop would start again from the beginning (Du Preez \& Du Preez, 2012).

According to the focus group study, the general advantage of having access to resources might also lead to negative symptoms in open-book assessment. These symptoms related to how time consuming it is to prepare for open-book assessment and reluctance on the part of the students to prepare thoroughly on account of the availability of answers in the resources they can take into the assessment venue (Du Preez \& Du Preez, 2012).

The focus group study indicated that preparing the resources for the open-book assessment (good preparation) might lead to excessive paging through textbooks during the assessment, leading in turn to disruption in the assessment venue (negative environment). This could result in a negative personal experience and could even be described as a personal hindrance. They understood this personal hindrance to be either the unnecessary checking of textbooks and notes because of the different approach, or a waste of time on account of unsatisfactory time management (Du Preez \& Du Preez, 2012).

\section{Semi-structured interviews}

\section{Data collection}

An interview is an interactive conversation between individuals. The main objective of a qualitative interview is to give the interviewer (researcher) insight into what the interviewee (participant) thinks, feels, experiences and perceives about a specific phenomenon (Henning, Van Rensburg, \& Smit, 2004), thereby understanding and acquiring a narrative of the lived world of the interviewee, related or relating to contrasting and/or complementary descriptions of a specific phenomenon (Kvale, 1996; Rapley, 2004) - in this case, open-book assessment.

The five interviewees were selected in order to gain specific information about perceptions of open-book assessment from an accessible group who had experienced this phenomenon and had something to say about it, as recommended by Cooper and Schindler (2003).

An appointment was made with each participant for an interview of one hour. Before the commencement of the interview, the interviewee was asked to sign a consent form. An interview plan was decided on beforehand, including closed questions (clarifying questions), various open questions on the definitions of the affinities compiled by the focus group study, and open-ended questions on the relationships between specific affinities. A collective system influence diagram (CSID) was then compiled for the relationships indicated by the interviewees.

\section{Collective system influence diagram (CSID)}

After completion of the interviews, the information provided by all five interviewees was used to compile a CSID. The classification of the affinities of the interviewees is summarised as tentative CSID assignments in Figure 3. 


\begin{tabular}{|l|l|}
\hline Affinity & Assignment \\
\hline Different approach & Primary driver \\
\hline Good preparation & Secondary driver \\
\hline Time management & Secondary driver \\
\hline Back-up & Secondary driver \\
\hline Negative symptoms & Secondary outcome \\
\hline Personal experience and hindrance & Secondary outcome \\
\hline General advantages & Secondary outcome \\
\hline Encouragement & Secondary outcome \\
\hline Negative environment & Primary outcome \\
\hline Improved quality of answers & Primary outcome \\
\hline
\end{tabular}

Figure 3. Tentative CSID assignments for all the interviews.

\section{Findings emerging from the interviewees' CSID}

Figure 4 illustrates the summarised perceptions of the interviewees and their experiences of open-book assessment. The ten affinities described by the focus group were used as a basis, and the interactive relationships between the different affinities provided by the interviewees are presented in this CSID.

The primary driver identified by all the interviewees was different approach. There were two primary outcomes in this CSID: negative environment and improved quality of answers. One feedback loop was identified in the system.

The feedback loop showed that good preparation for an open-book assessment included going through the material that could be taken into the assessment and getting it ready, as well as studying the material for hands-on knowledge during the assessment. According to all interviewees, this would help a student with better time management before and during the assessment. The interviewees believed that good time management during the study period ensures that adequate time is spent on preparing the back-up. The materials available as a back-up during the assessment lead to general advantages arising from open-book assessment. The interviewees perceived a general advantage to be the fact that the back-up is a visual tool for accessing detail, or checking changes in laws. Having access to detail (general advantage) might create a feeling of optimism and encouragement. It could give the student motivation (encouragement) during the assessment, but it could also become a security blanket leading to a laid-back attitude/laziness (negative symptom) when preparing for openbook assessment. Laziness (negative symptom) would influence students' preparation for the assessment.

In Figure 4, the affinity negative symptom is shown to influence good preparation (discussed as part of the feedback loop), as well as personal experience and hindrance. If there is excessive checking of answers in the available material (personal experience and hindrance), this could be disruptive in the assessment venue, which could create a negative environment. Although the availability of material (personal experience and hindrance) could lead to a disruption, it could also improve the quality of answers, because checking material might bring to mind details forgotten or not memorised. 


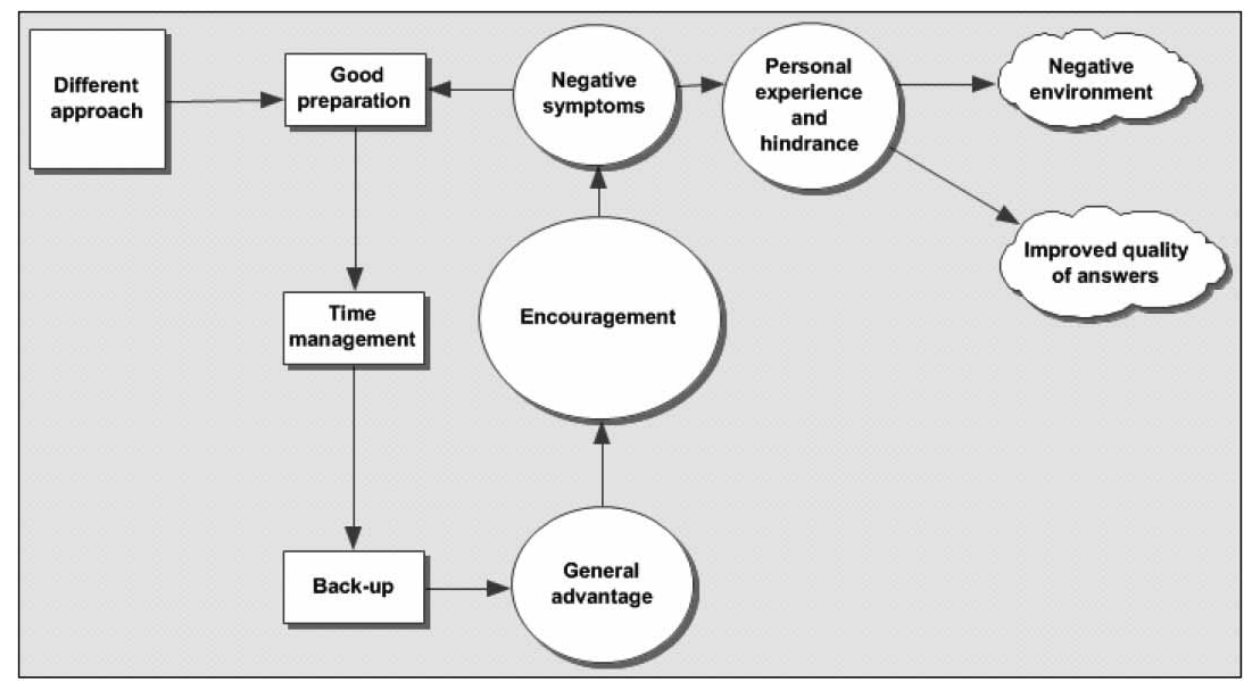

Figure 4. Final CSID for all the interviews.

\section{Discussion}

In this section, the individual affinities are discussed in detail, providing a summarised comparison of the findings in the focus group study (see Figure 2; Du Preez \& Du Preez, 2012) and the interviewees' representations (see Figure 4) in terms of the affinities' placement, relative impact and influence on other affinities.

\section{Affinity 1 - good preparation}

Figure 5 represents Affinity 1's placement, relative impact and influence on the other affinities, according to Figures 2 and 4.

According to Figure 5, good preparation is a driver in both the focus group and the interviewees' systems. The focus group perceived good preparation as a source of encouragement for students because when students prepare well, they feel encouraged to write the assessment. This leads to an improvement in the quality of answers and then the students prepare with more enthusiasm the next time, which restarts the process from the beginning. However, students' paging through books and related general activity in the assessment venue can result in a negative environment. Lastly, good preparation influences the

\begin{tabular}{|l|l|l|}
\hline Constituency & Focus group & Interviewees \\
\hline Placement in SID & Secondary driver & Secondary driver \\
\hline Direct impact & $\begin{array}{l}\text { Negative environment } \\
\text { Encouragement } \\
\text { Back-up }\end{array}$ & Time management \\
\hline Direct influence & Improved quality of answers & $\begin{array}{l}\text { Different approach } \\
\text { Negative symptoms }\end{array}$ \\
\hline
\end{tabular}

Figure 5. Summarised comparison for Affinity $1-$ good preparation. 


\begin{tabular}{|l|l|l|}
\hline Constituency & Focus group & Interviewees \\
\hline Placement in SID & Secondary driver & Secondary driver \\
\hline Direct impact & General advantage & General advantage \\
\hline Direct influence & Good preparation & Time management \\
\hline
\end{tabular}

Figure 6. Summarised comparison for Affinity 2 - back up.

availability of the resources (back-up) during an assessment. The better the preparation of the resources, the better they are used.

The interviewees agreed that a different approach is necessary in order to be well prepared for an open-book assessment. If material is available, as in an open-book assessment, students may decide that thorough preparation is not necessary. This could lead to the negative symptoms of open-book assessment - for example, lazy and underprepared students. Good preparation ensures that the time available during the assessment is optimally used, thus resulting in good time management.

\section{Affinity 2 - back-up}

Figure 6 represents Affinity 2's placement, relative impact and influence on the other affinities, according to Figures 2 and 4.

According to Figure 6, back-up is perceived by both sets of participants as a driver. For the focus group, use of the back-up depends on how well the student has prepared the material. The better prepared the student, the more efficient the use of the back-up during an assessment. Using the back-up results in general advantages - for example, memorising is unnecessary and problems with the ever-changing Tax Act can be avoided.

The interviewees stated that time management would be the driving force behind the use of a back-up. The accessibility of a back-up during the assessment leads to general advantages for students.

\section{Affinity 3 - encouragement}

Figure 7 represents Affinity 3's placement, relative impact and influence on the other affinities, according to Figures 2 and 4.

According to Figure 7, the focus group perceived encouragement as a driver, whereas the interviewees held encouragement to be an outcome. The focus group recognised that good preparation generates a feeling of optimism (encouragement) in students that can result in an improvement in the quality of answers. This feedback loop leads to positive processes that result in more motivated students.

\begin{tabular}{|l|l|l|}
\hline Constituency & Focus group & Interviewees \\
\hline Placement in SID & Secondary driver & Secondary outcome \\
\hline Direct impact & Improved quality of answers & Negative symptoms \\
\hline Direct influence & Good preparation & General advantage \\
\hline
\end{tabular}

Figure 7. Summarised comparison for Affinity 3 - encouragement. 


\begin{tabular}{|l|l|l|}
\hline Constituency & Focus group & Interviewees \\
\hline Placement in SID & Secondary outcome & Secondary outcome \\
\hline Direct impact & $\begin{array}{l}\text { Negative symptoms } \\
\text { Improved quality of answers }\end{array}$ & Encouragement \\
\hline Direct influence & Back-up & Back-up \\
\hline
\end{tabular}

Figure 8. Summarised comparison for Affinity 4 - general advantages.

For the interviewees, encouragement is influenced by general advantages. One of these advantages is the fact that memorising every detail is reduced. Although it is an advantage, it may lead to a false sense of security (encouragement) and give rise to laziness (negative symptoms).

\section{Affinity 4 - general advantages}

Figure 8 represents Affinity 4's placement, relative impact and influence on the other affinities, according to Figures 2 and 4. According to Figure 8, both sets of participants see general advantages as an outcome.

The focus group and interviewees agreed that having a back-up leads to several general advantages. Having a back-up stimulates an optimistic feeling in the interviewees because it is not necessary to depend only on rote memory (a general advantage), as the material (back-up) is at hand to assist candidates. This perception encourages students before and during an assessment.

The focus group presented the same argument, but they did not perceive this positively, as they thought that removing the rote memorising of knowledge (general advantage) may lead to negative symptoms in the form of a laid-back laziness and an attitude of "I don't need to study". Although the focus group had a negative perception on this point, they believed that the material available to them (back-up) would result in an improvement in the quality of answers presented.

\section{Affinity 5 - improved quality of answers}

Figure 9 represents Affinity 5's placement, relative impact and influence on the other affinities, according to Figures 2 and 4.

According to Figure 9, the focus group perceived this affinity as a driver with a direct influence from the general advantages of open-book assessment. Because students have access to the theory, an improved and better-formulated answer can be written. Time

\begin{tabular}{|l|l|l|}
\hline Constituency & Focus group & Interviewees \\
\hline Placement in SID & Secondary driver & Primary outcome \\
\hline Direct impact & Good preparation & \\
\hline Direct influence & $\begin{array}{l}\text { Encouragement } \\
\text { General advantages }\end{array}$ & Personal experience and hindrance \\
\hline
\end{tabular}

Figure 9. Summarised comparison for Affinity 5 - improved quality of answers. 
constraints are an important factor in the process of delivering an improved answer, so the necessity for good preparation is emphasised. Students tend to feel more encouraged by good preparation and this positive attitude leads to an improvement in the quality of answers.

In contrast with this perception of the affinity, the interviewees concluded that the improvement in the quality of answers was a final outcome of the system, with its direct influence coming from personal experience and hindrance. These students perceived open-book assessment as difficult and demanding and reported that they tended to waste time searching through the material in an effort to improve the quality of their answers.

\section{Affinity 6 - negative symptoms}

Figure 10 represents Affinity 6's placement, relative impact and influence on the other affinities, according to Figures 2 and 4 . As Figure 10 shows, both sets of participants agreed that negative symptoms of open-book assessment are an outcome of their system.

The focus group concluded that the general advantages of open-book assessment lead to the negative symptoms of this assessment type. The availability of material during the assessment and a decrease in the necessity of memorising the facts could make students lazy and allow them to think they can look for the answer during the assessment. These negative symptoms appear to be the result of assumptions and uninformed perceptions.

The interviewees perceived the affinity described as encouragement to lead to negative symptoms of open-book assessment. When students experience less anxiety and stress (encouragement), they tend to decrease their preparation time and become lazy and laid back (negative symptoms). This perception has a detrimental effect on good preparation, as students seem to misunderstand the purpose of open-book assessment. The interviewees experienced the assessment as difficult and demanding and concluded that it being an open-book assessment added no value (personal experience and hindrance).

\section{Affinity 7 - negative environment}

Figure 11 represents Affinity 7's placement, relative impact and influence on the other affinities, according to Figures 2 and 4. According to Figure 11, the two sets of participants disagreed on the placement of the affinity within the system. The focus group perceived the negative environment as a driver, while the interviewees concluded that it represented an outcome.

For the focus group, the negative environment was influenced by (a lack of) good preparation. The fact that it is advisable for students to prepare the material to be taken into the

\begin{tabular}{|l|l|l|}
\hline Constituency & Focus group & Interviewees \\
\hline Placement in SID & Primary outcome & Secondary outcome \\
\hline Direct impact & & $\begin{array}{l}\text { Good preparation } \\
\text { Personal experience and hindrance }\end{array}$ \\
\hline Direct influence & General advantages & Encouragement \\
\hline
\end{tabular}

Figure 10. Summarised comparison for Affinity 6 - negative symptoms. 


\begin{tabular}{|l|l|l|}
\hline Constituency & Focus group & Interviewees \\
\hline Placement in SID & Secondary driver & Primary outcome \\
\hline Direct impact & $\begin{array}{l}\text { Personal experience and } \\
\text { hindrance }\end{array}$ & \\
\hline Direct influence & Good preparation & $\begin{array}{l}\text { Personal experience and } \\
\text { hindrance }\end{array}$ \\
\hline
\end{tabular}

Figure 11. Summarised comparison for Affinity 7 - negative environment.

assessment by flagging, highlighting and marking the sections for quick referencing during the assessment (good preparation) could lead to a negative environment where unnecessary use of the material could be a distraction. Paging through the material wastes time and creates the feeling that the assessment type adds no value (personal experience and hindrance).

For the interviewees, the affinity personal experience and hindrance had a direct influence on creating a negative environment. When students do not trust themselves, they tend to check all their answers. The consequence is excessive checking, which causes distractions in the venue (negative environment).

\section{Affinity 8 - personal experience and hindrance}

Figure 12 represents Affinity 8's placement, relative impact and influence on the other affinities, according to Figures 2 and 4. As Figure 12 shows, the focus group perceived this affinity as being influenced equally by other affinities and impacting in turn on other affinities, whereas the interviewees observed that personal experience and hindrances are an outcome of the system.

According to the focus group, the creation of a negative environment influences students' personal experience. This has an impact on the approach followed before and during the assessment. A different approach is necessary because of access to supporting material during the assessment. Personal experiences and hindrances as an affinity focuses students' attention on the necessity for time management and influences it directly. Students need to practise time management before and during an assessment.

The interviewees recognised the negative symptoms of open-book assessment as the main influence on students' personal experience. The knowledge that the supporting material is available may make students lazy, which may affect their personal experience. Students' personal experience influences the environment negatively during the assessment, because lazy students page through the supporting material more often in an

\begin{tabular}{|l|l|l|}
\hline Constituency & Focus group & Interviewees \\
\hline Placement in SID & Pivot & Secondary outcome \\
\hline Direct impact & Time management & Improved quality of answers \\
& Different approach & Negative environment \\
\hline Direct influence & Negative environment & Negative symptoms \\
\hline
\end{tabular}

Figure 12. Summarised comparison for Affinity 8 - personal experience and hindrance. 


\begin{tabular}{|l|l|l|}
\hline Constituency & Focus group & Interviewees \\
\hline Placement in SID & Primary outcome & Primary driver \\
\hline Direct impact & & Good preparation \\
\hline Direct influence & Personal experience and hindrance & \\
\hline
\end{tabular}

Figure 13. Summarised comparison for Affinity 9 - different approach.

attempt to locate the correct answer. Through this personal experience, the quality of answers may decrease, as students attempt to find a generic answer instead of developing their own.

\section{Affinity 9 - different approach}

Figure 13 represents Affinity 9's placement, relative impact and influence on the other affinities, according to Figures 2 and 4. According to Figure 13, the focus group and the interviewees held different perceptions of the different approach affinity. For the interviewees, the affinity was the driver of the whole system. By contrast, the focus group concluded that it was the final outcome (result) of the system.

The interviewees argued that a different approach is necessary when confronted with open-book assessment, and that the first area for change would be students' attitude towards preparation. Good preparation is therefore vital for success during an openbook assessment.

The focus group thought that an open-book assessment is more demanding and difficult (personal experience and hindrance) and leads to a different approach when preparing for this type of assessment.

\section{Affinity 10 - time management}

Figure 14 represents Affinity 10's placement, relative impact and influence on the other affinities, according to Figures 2 and 4 . As Figure 14 indicates, the focus group saw time management as antcome of the system, while the interviewees identified it as a driver.

According to the focus group, students tend to waste time when checking answers because they do not trust in their own ability (personal experience and hindrance). Students' self-esteem has a direct impact on their time management.

The interviewees thought that good preparation influences time management directly. If students are thoroughly prepared, time management is optimal during the assessment. When students are fully prepared and time is managed correctly, then the back-up can be employed to its full potential.

\begin{tabular}{|l|l|l|}
\hline Constituency & Focus group & Interviewees \\
\hline Placement in SID & Primary outcome & Secondary driver \\
\hline Direct impact & & Back-up \\
\hline Direct influence & Personal experience and hindrance & Good preparation \\
\hline
\end{tabular}

Figure 14. Summarised comparison for Affinity 10 - time management. 


\section{Conclusion}

The perceptions of students of open-book assessments before and during such an assessment influence their actions, which ultimately determine their level of success (Struyven et al., 2002). The purpose of this study was to compare students' perceptions of openbook assessment before and after experiencing such assessment.

The earlier focus group, in which students who had not before been exposed to openbook assessment participated (Du Preez \& Du Preez, 2012), and the interviewees in the current study, who had been exposed to open-book assessment, agreed that good preparation and a back-up are drivers towards success in open-book assessment. This finding is in line with the literature arguing that open-book assessment seems to create a better understanding of the contents of a subject area and therefore prepares students for real-life situations (Baillie \& Toohey, 1997; Durham, 1990; Feller, 1994; Theophilides \& KoutseliniIoannidou, 2000). The IQA shows that the focus group and the interviewees concurred on a general advantage and negative symptoms of open-book assessment as outcomes.

However, the focus group and the interviewees disagreed on the status of a different approach towards open-book assessment in comparison to closed-book assessment. The interviewees experienced the concept of a different approach as the primary driver of success, while the focus group saw a different approach as the final outcome of the process. In the experience of the interviewees, a different approach seems to be the starting point of the successful completion of open-book assessment. Secondary differences were perceived for encouragement, improved quality of answers, negative environment, personal experience and hindrance and time management. These discrepancies suggest that the perceptions of the focus group may not have been completely realistic.

The perception that was highlighted through several comments by members of the focus group and the interviewees was the encompassing reality that good time management is the pivot for success during an open-book assessment. Appropriate time allocation during the preparation stage includes time for studying the contents and preparing the material. During the assessment itself, the student should be aware of the material available, but may only use it as a back-up for emergencies.

For Taxation, students are allowed to use the Tax Act as back-up material. This source seems to create a problem, because the text has to be interpreted beforehand due to the complexity of the contents. This course of action requires additional time. When students are too dependent on the Tax Act (they rely on it being available to them, instead of being familiar with it beforehand), they waste time reading and understanding the contents during the assessment. Another potential problem with the Tax Act is the constant changes in legislation, with the obvious result that the Tax Act must be updated. Thus, with every update, the Tax Act as back-up material must be prepared again, with flags and highlights.

When open-book assessment is introduced, students should be assisted in following a different approach. The disparity between the perceptions of the focus group and the experience of the interviewees may be addressed through workshops, discussion groups, multimedia programmes, mentorship programmes, debriefing, consultation, focused social networking, simulated and "real-life" assessments, as well as awareness programmes, and could even be built into their curriculum. These proposed methods of assistance could be applied to students, lecturers and professional bodies.

In conclusion, the current study shows that the perceptions of students on open-book assessment prior to exposure or experience of open-book assessment differ from those of students who have had experience of open-book assessment. This emphasises the fact that every assessment type requires a different approach. 
Future research could focus on using a larger group of participants - for example, including more students by using a questionnaire with questions specifically converging on the affinities that emerged from the focus group study and discussed by the interviewees as reported in this article. This could contribute to bringing about a deeper understanding of students' perceptions both before and after exposure to open-book assessments. This would create ample opportunity for applying a mixed-methods methodology.

\section{Disclosure statement}

No potential conflict of interest was reported by the authors.

\section{Note}

1. Older primary references are included because many recent publications still refer to these landmark studies.

\section{References}

AERA (American Educational Research Association). (1985). Standards for educational and psychological testing. Washington, DC: AERA.

Agarwal, P. K., \& Roediger, H. L. III. (2011). Expectancy of an open-book test decreases performance on a delayed closed-book test. Memory, 19, 836-852.

Baillie, C., \& Toohey, S. (1997). The "power test": Its impact on student learning in a material science course for engineering students. Assessment and Evaluation in Higher Education, 22, 33-48.

Boniface, D. (1985). Candidates' use of notes and textbooks during an open-book examination. Educational Research, 27, 201-209.

Cooper, D. R., \& Schindler, P. S. (2003). Business research methods (International 8th ed.). Boston, MA: McGraw Hill.

Coetzee, S., \& Oberholzer, R. (2012). Education general information. In E. Evans, R. Juchau and RMS Wilson (Eds.), The interface of Accounting Education and professional training (pp. 99120). Abingdon: Routledge.

Creswell, J. W. (2002). Educational research: Planning, conducting, and evaluating quantitative and qualitative research. Upper Saddle River, NJ: Merrill Prentice Hall.

Du Preez, H., \& Du Preez, C. S. (2012). Taxation students' perceptions of open-book assessment prior to the qualifying examination of South African chartered accountants. SA Journal of Accounting Research, 26, 119-142.

Durham, K. (1990). The open-book examination. Foundation for Education, Science and Technology, 24,59

Eilertsen, T. V., \& Valdermo, O. (2000). Open-book assessment: A contribution to improved learning? Studies in Educational Evaluation, 26, 91-103.

Feller, M. (1994). Open-book testing and education for the future. Studies in Educational Evaluation, 20, 235-238.

Henning, E., Van Rensburg, W., \& Smit, B. (2004). Finding your way in qualitative research. Pretoria: Van Schaik.

Karagiannopoulou, E., \& Milienos, F. S. (2013). Exploring the relationship between experienced students' preference for open- and closed-book examinations, approaches to learning and achievement. Educational Research and Evaluation, 19, 271-296.

Kelly, R. (2013). Alternative assessment methods for the online classroom. Online Classroom, 13(7): $1-8$.

Koutselini-Ioannidou, M. (1997). Testing and life-long learning: Open-book and closed book examination in a university course. Studies in Educational Evaluation, 23, 131-139.

Kvale, S. (1996). Interviews: An introduction to qualitative research interviewing. Thousand Oaks, CA: Sage.

Mampane, R., \& Bouwer, C. (2011). The influence of township schools on the resilience of their learners. South African Journal of Education, 31, 114-126. 
Msila, V. (2011). Open-book examinations in a distance (teacher) education programme: South African teacher-learner experiences. International Journal of Distance Education Technologies, 9(3), 1-12.

Northcutt, N., \& McCoy, D. (2004). Interactive qualitative analysis: A systems method for qualitative research. London: Sage.

Rapley, T. (2004). Interviews. In C. Seale, G. Gobo, J. F. Gubrium, \& D. Silverman (Eds.), Qualitative research practice (pp. 15-33). London: Sage.

Reynolds, C. R., Livingston, R. B., \& Willson, V. (2006). Measurement and assessment in education. Boston, MA: Pearson Education.

SAICA (The South African Institute of Chartered Accountants). (2009). Open-book policy: Updated and approved by EDCO, February: \#247318. Johannesburg: SAICA

Struyven, K., Dochy, F., \& Janssens, S. (2002, August). Students' perceptions about assessment in higher education: A review. Paper presented at the Joint Northumbria/Earli SIG Assessment and Evaluation Conference, Newcastle, UK

Theophilides, C., \& Dionysiou, O. (1996). The major functions of the open-book examination at the university level: A factor analytic study. Studies in Educational Evaluation, 22, 157-170.

Theophilides, C., \& Koutselini-Ioannidou, M. (2000). Study behaviour in the closed-book and the open-book examination: A comparative analysis. Educational Research and Evaluation, An International Journal on Theory and Practice, 6, 379-393.

Westerkamp, A. C., Heijne-Penninga, M., Kuks, J. B. M., \& Cohen-Schotanus, J. (2013). Open-book tests: Search behaviour, time used and test scores. Medical Teacher, 35, 330-332. 